\title{
DIFFUSION OF GASES IN AIR AND ITS AFFECT ON OXYGEN DEFICIENCY HAZARD ABATEMENT
}

\author{
J. C. Theilacker and M. J. White \\ Fermi National Accelerator Laboratory \\ Batavia, IL, 60510, USA
}

\begin{abstract}
Density differences between air and released gases of cryogenic systems have been used to either require special oxygen deficiency hazard (ODH) control measures, or as a means of abatement. For example, it is not uncommon to assume that helium spills will quickly collect at the ceiling of a building or enclosure and will efficiently exit at the nearest vertical penetration or vent.

Oxygen concentration reduction was found to be detectable during a localized helium spill throughout the entire $6.3 \mathrm{~km}$ Tevatron tunnel. This prompted us to perform diffusion tests in air with common gases used at Fermilab. The tests showed that gases, more readily than expected, diffused through an air column in the direction opposing buoyancy. Test results for helium and sulfur hexafluoride are presented.

A system of tests were performed to better understand how easily released gases would fully mix with air and whether they remained fully mixed. The test results have been applied to a new system at Fermilab for ODH abatement.
\end{abstract}

KEYWORDS: Diffusion, ODH, Safety, Asphyxiate

PACS: 51.20 .

\section{INTRODUCTION}

Process systems with large inventories of stored gases or cryogenic liquids require control measures to ensure personnel safety for oxygen deficiency in the case of a release [1]. Analyses for the oxygen deficiency hazard $(\mathrm{ODH})$ potential have been done considering release gas conditions ranging from fully stratified to fully mixed with the building or enclosure air, depending on the underlying situation. It is not uncommon in systems utilizing gases with a density considerably different than air to assume full stratification. This is particularly true in helium-based systems. It is common to rely on 


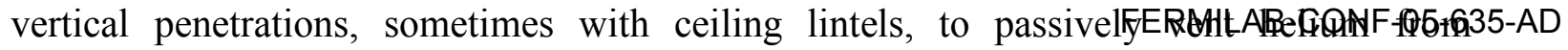
buildings or underground enclosures.

A moderate helium spill in the $6.3 \mathrm{~km}$ circumference Tevatron accelerator tunnel on December 5, 2003 brought considerable uncertainty to a fully stratified assumption. A cracked ceramic on a 50 ampere correction magnet power lead was the source of the leak. Operational difficulties, not oxygen monitors, identified that there was a problem within a magnet string in the normally unmanned Tevatron tunnel. Following the repair, logged oxygen monitor data was plotted to investigate the path of the released helium.

The Tevatron tunnel has three oxygen monitors approximately every $250 \mathrm{~m}$; one at the floor for nitrogen, one at the ceiling for helium and one at the top of the exit staircase for helium. An exhaust fan, controlled by the oxygen monitor is located at the top of the staircase. Besides the staircase, there is also a $25 \mathrm{~cm}$ diameter vertical penetration to the satellite refrigerator at the same intervals. There is a nominal $3 \mathrm{~km} / \mathrm{h}$ circulating air flow around the tunnel. Outside air is only passively mixed with the tunnel air, unless oxygen monitors reach $18 \%$ or lower when the staircase exhaust fans are automatically turned on. During the December 2003 spill, the lowest oxygen monitor reached only $191 / 2 \%$ and therefore active ventilation was not initiated.

To our surprise, the floor, ceiling and staircase oxygen monitors just downstream of the spill all read the same, suggesting no stratification. Further investigation revealed that an oxygen dip could be seen traveling around the entire $6.3 \mathrm{~km}$ tunnel, back to the initial source! The dip in oxygen concentration was reduced at each $250 \mathrm{~m}$ interval, presumably due to passive outside air mixing. FIGURE 1 shows that it took $4 \frac{3}{4}$ hours for the helium wave to travel around the $6.3 \mathrm{~km}$ tunnel. The source of the leak was within the downstream magnet string of the $\mathrm{C} 1$ refrigerator as shown in the figure. The dip in oxygen concentration was diluted to only $0.1 \%$ upon returning to the initial source. Throughout the $6.3 \mathrm{~km}$ journey, common oxygen readings at the floor, ceiling and the top of the staircase suggested that the helium remained fully mixed with the tunnel air.

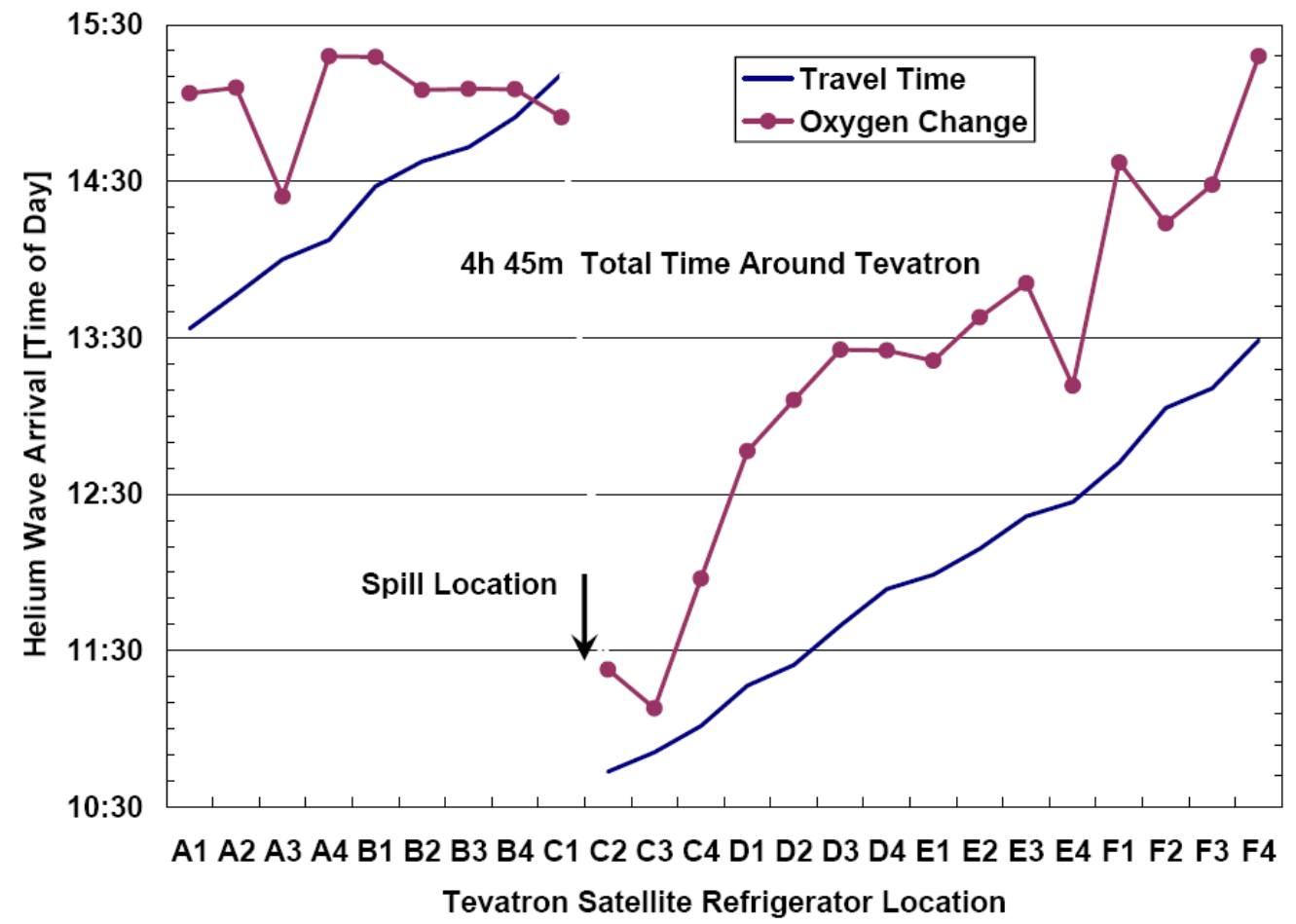

0.00

$-0.25$

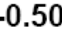

$-0.75$

FIGURE 1. Helium spill wave traveling around the $6.3 \mathrm{~km}$ Tevatron tunnel. 
This study was performed in order to better understand how effective mass transfer due to gas diffusion is able to counteract buoyancy differences. Gases used within ODH areas at Fermilab were investigated, including helium, argon, nitrogen, and sulfur hexafluoride.

\section{SYSTEM DESCRIPTION}

To measure gas diffusion in air, a $180 \mathrm{~cm}$ long test cell was constructed from $10 \mathrm{~cm}$ ID pipe. One end of the test cell was welded closed with a plate which incorporated a method for injecting the sample gas, as shown in FIGURE 2. Four oxygen cells were mounted within the test cell at a distance of $15 \mathrm{~cm}, 60 \mathrm{~cm}, 105 \mathrm{~cm}$ and $150 \mathrm{~cm}$ from the closed end of the cell. With sample gases lighter than air, the cell was oriented vertically with the closed end up. The cell was oriented with the closed end down while using sample gases heavier than air. An air baffle was placed around the open end of the pipe in order to prevent normal air circulation within the building from affecting the test cell.

Oxygen monitors were data logged in a laptop PC at an interval of $10 \mathrm{~Hz}$. Data within slow changing regions were considerably thinned in order to keep data files a reasonable size. The oxygen cells used were the type that responds correctly with a helium background gas [2]. Sample gases were injected into the closed end of the cell. The sample gas supply was then isolated to ensure that valve leakage did not influence the results. Oxygen monitors were used to indirectly measure the diffusion of the sample gas relative to air.

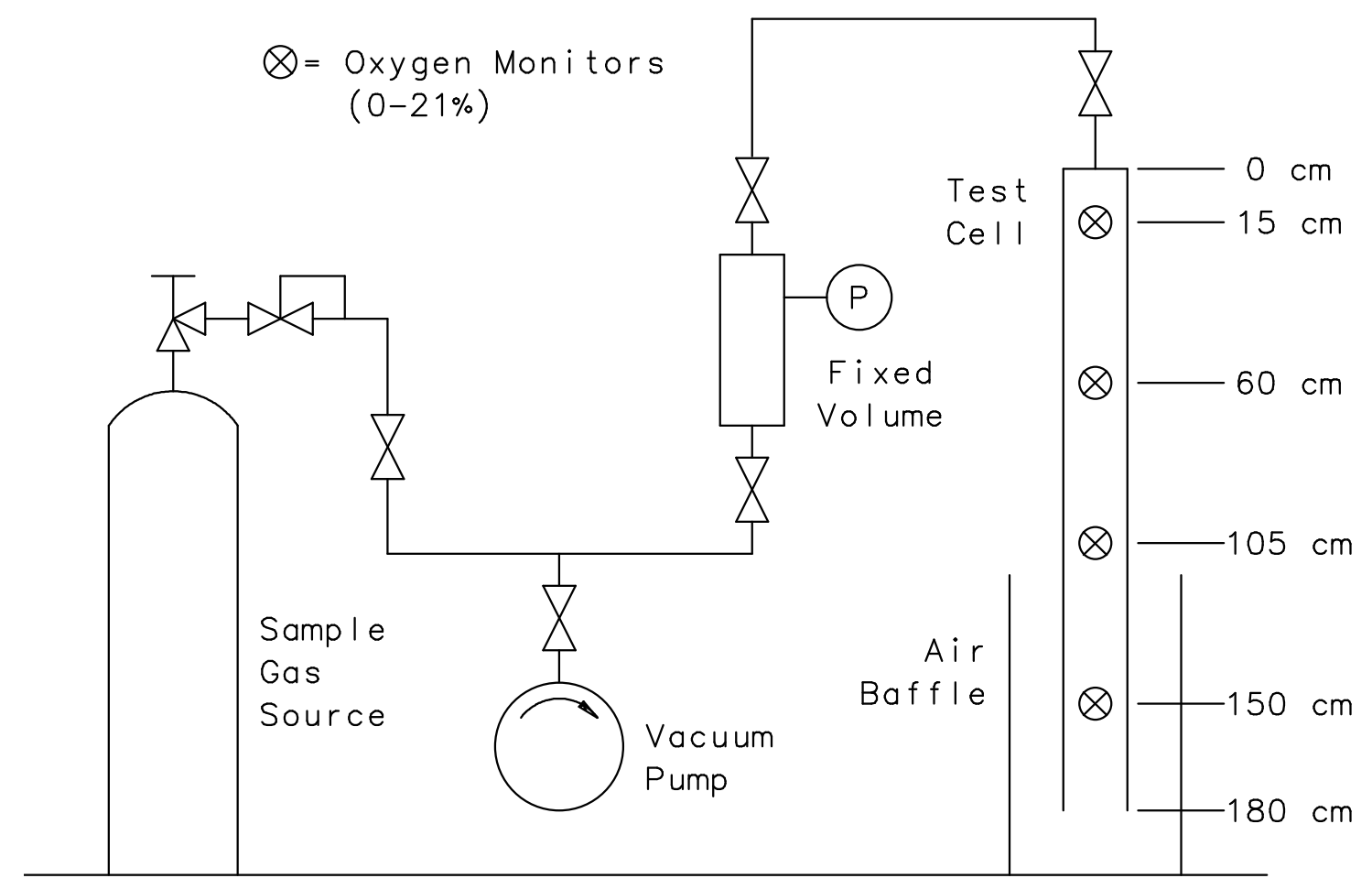

FIGURE 2. Gas diffusion test schematic shown in the configuration for testing gases lighter than air. 


\section{TEST RESULTS}

Initially, fixed volumes of helium gases were injected into the cell, representing onethird its volume. This was in an attempt to represent how quickly a fixed volume of released gas would diffuse throughout a still room. The results are shown in FIGURE 3. The figure shows that it took about two hours for a consistent oxygen, and thus helium concentration gradient to be established. From that point on, the helium virtually completely diffused out of the bottom of the test cell over the next sixteen hours.

The relative ease at which helium completely escaped out the bottom of the cell initially surprised us. To better investigate this, it was decided to change the test procedure to totally flood the cell with the sample gas. FIGURE 4 shows the results with the test cell initially totally flooded with helium. This figure shows a steep change in oxygen concentration in the sensor $150 \mathrm{~cm}$ from the closed end of the cell. This "wave" of helium diffusing out and air diffusing in, flattens out as it travels deeper into the cell due to a reduction in the driving term, concentration gradient. The time scales of FIGURES 3 and 4 were kept the same in order to show the consistency in the diffusion once a uniform concentration gradient was established in the fixed volume test of FIGURE 3.

An analytical model was developed in an attempt to predict the diffusion profiles. To simplify the model to a manageable degree, a binary diffusion model was used [3]. This resulted in the need to consider air as a single gas with a molecular weight of 29 in order to calculate a diffusion coefficient between air and the sample gas. Diffusion coefficients were calculated using Engineering Equation Solver (EES) [4]. A 75 node finite difference model of the test cell was developed and solved using Microsoft ${ }^{\circledR}$ Excel.

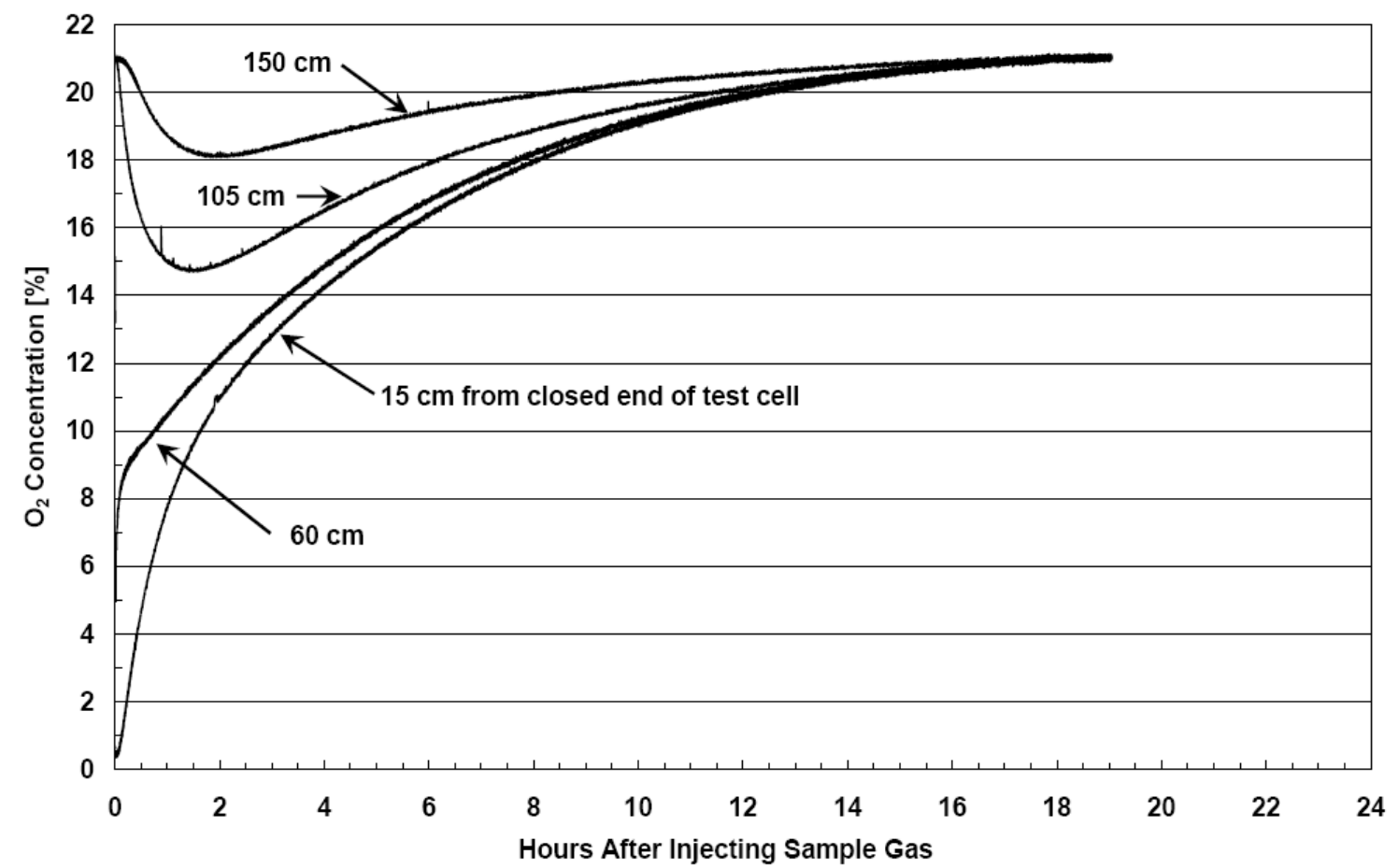

Figure 3. Helium gas diffusion in air following injecting a fixed volume of helium equal to one-third the test cell volume. 


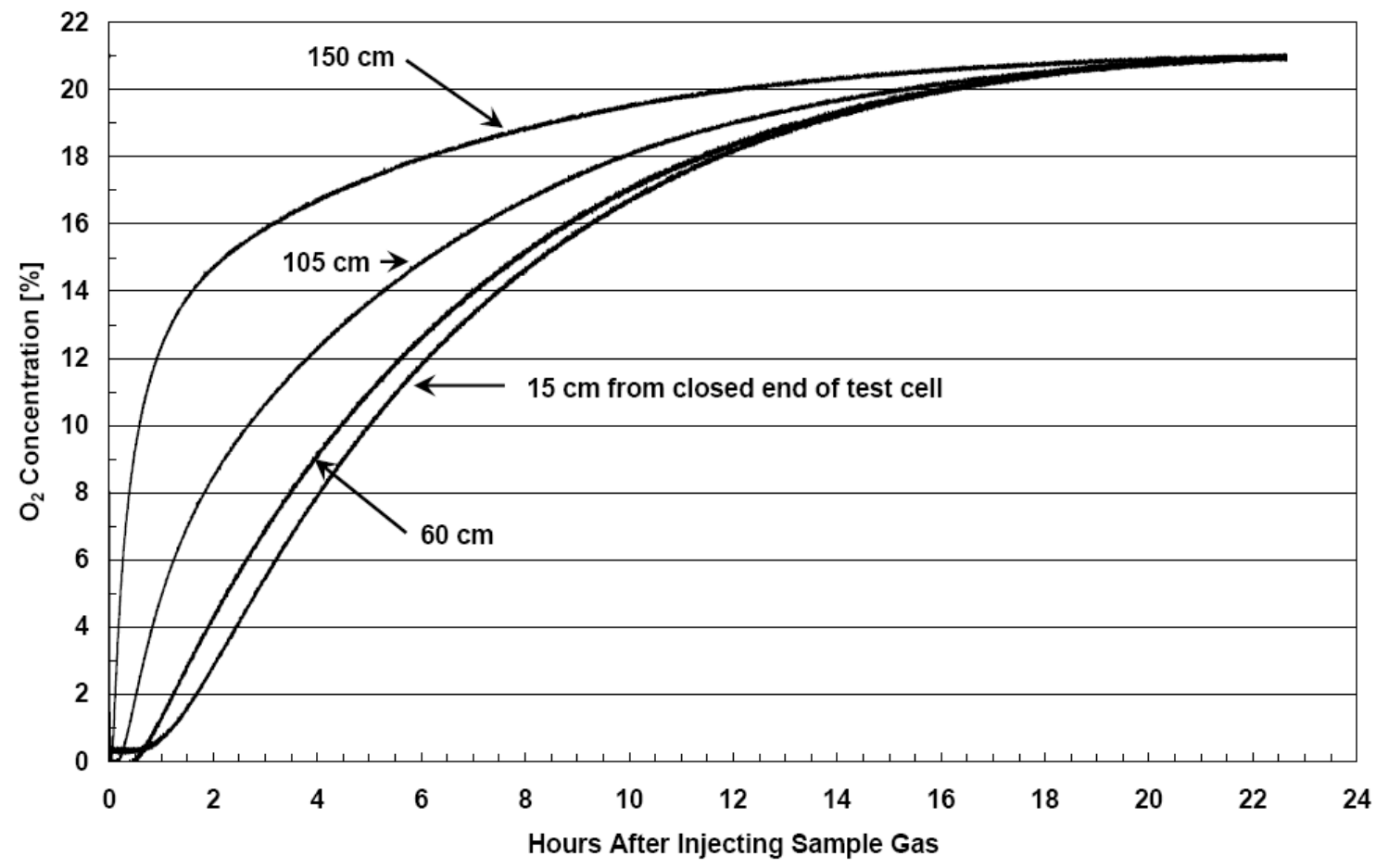

Figure 4. Helium gas diffusion in air following flooding the test cell with helium.

FIGURE 5 compares the analytical model with two of the oxygen sensor locations (15 $\mathrm{cm}$ and $150 \mathrm{~cm}$ from the closed end) from the helium diffusion test of FIGURE 4 . The figure shows good agreement with experimental results, with the simulation slightly over predicting the diffusion.

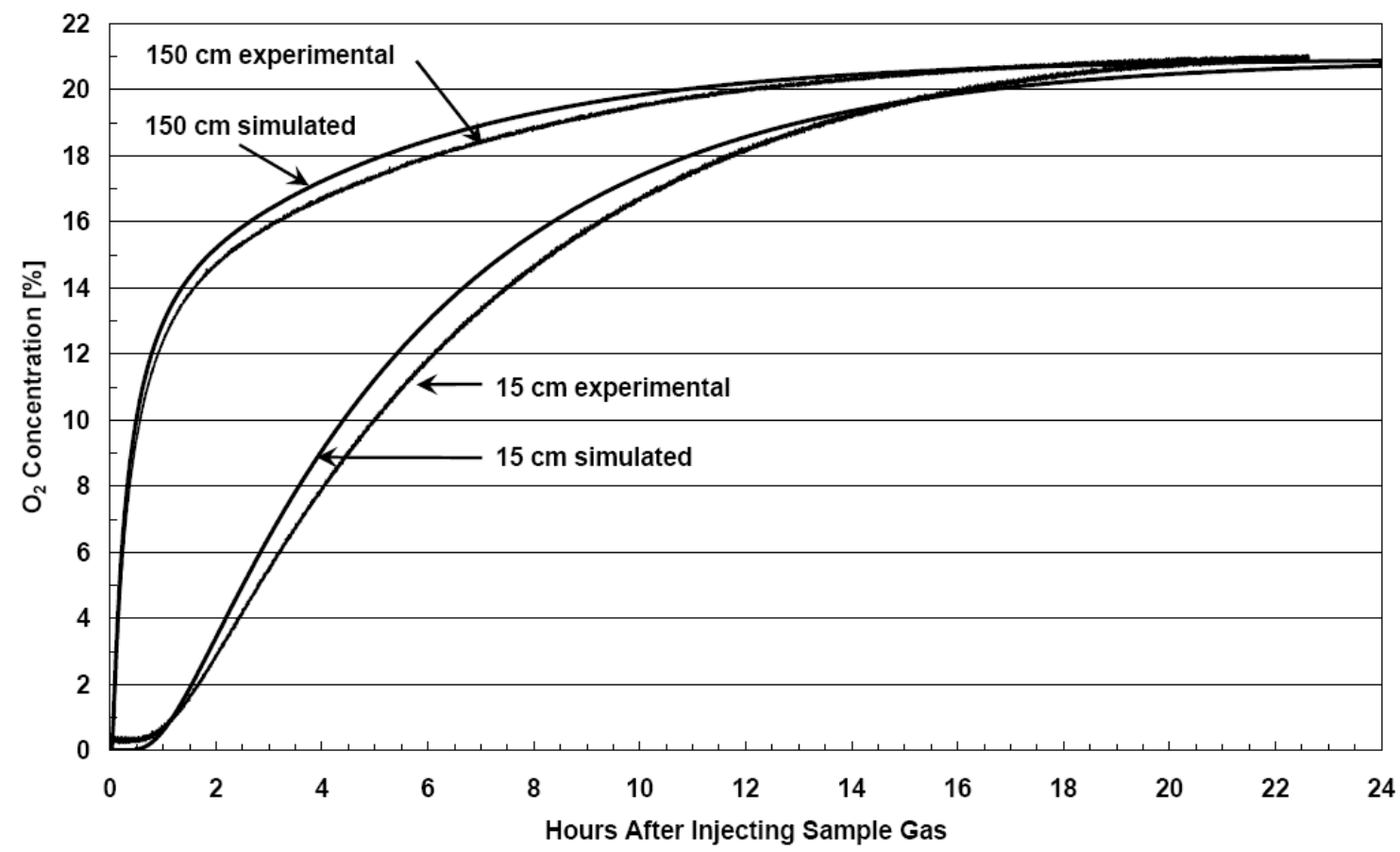

Figure 5. Comparison of simulated and experimental helium diffusion in air. 
A Pelletron accelerator is being commissioned at Fermilab for electron cooling of a stored antiproton beam. The Pelletron accelerator is housed within a $3.7 \mathrm{~m}$ diameter, $7.6 \mathrm{~m}$ long vessel, pressurized to $0.6 \mathrm{MPa}$ with sulfur hexafluoride $\left(\mathrm{SF}_{6}\right)$. This amounts to $490 \mathrm{~m}^{3}$ of $\mathrm{SF}_{6}$ at standard atmosphere. As a result, special $\mathrm{ODH}$ considerations need to be made for this gas, which has a density five times that of air.

Results of a diffusion test for $\mathrm{SF}_{6}$ and air are shown in FIGURE 6. Straight lines in the middle of the data are a result of an unexpected stoppage of the data logger over a weekend. The logger was restarted Monday morning. With a heavy sample gas, the test cell was configured with the closed end down.

The shape of the curves in FIGURE 6 is similar to that of helium, although the time duration is five days as opposed to one day in FIGURES 3-5 for helium. The slower gas diffusion is a direct result of the larger molecular weight as shown in [3]. The slower gas diffusion also has the effect of slightly flattening out the curves.

Gas diffusion simulation for $\mathrm{SF}_{6}$ proved to be as successful as the helium simulation in predicting the experimental data. This was not the case with all gases used in the test cell. The model proved to be better at predicting the diffusion of gases with a molecular weight considerably different than air, such as helium and $\mathrm{SF}_{6}$. Diffusion tests using argon or nitrogen as the release gas proved to be more difficult to simulate. The experimental results using these gases also did not exhibit the uniform diffusion curves shown by helium and $\mathrm{SF}_{6}$. It is suspected that these gases are more susceptible to changes in building pressure or building air flow, despite having the same air baffling system at the open end of the test cell.

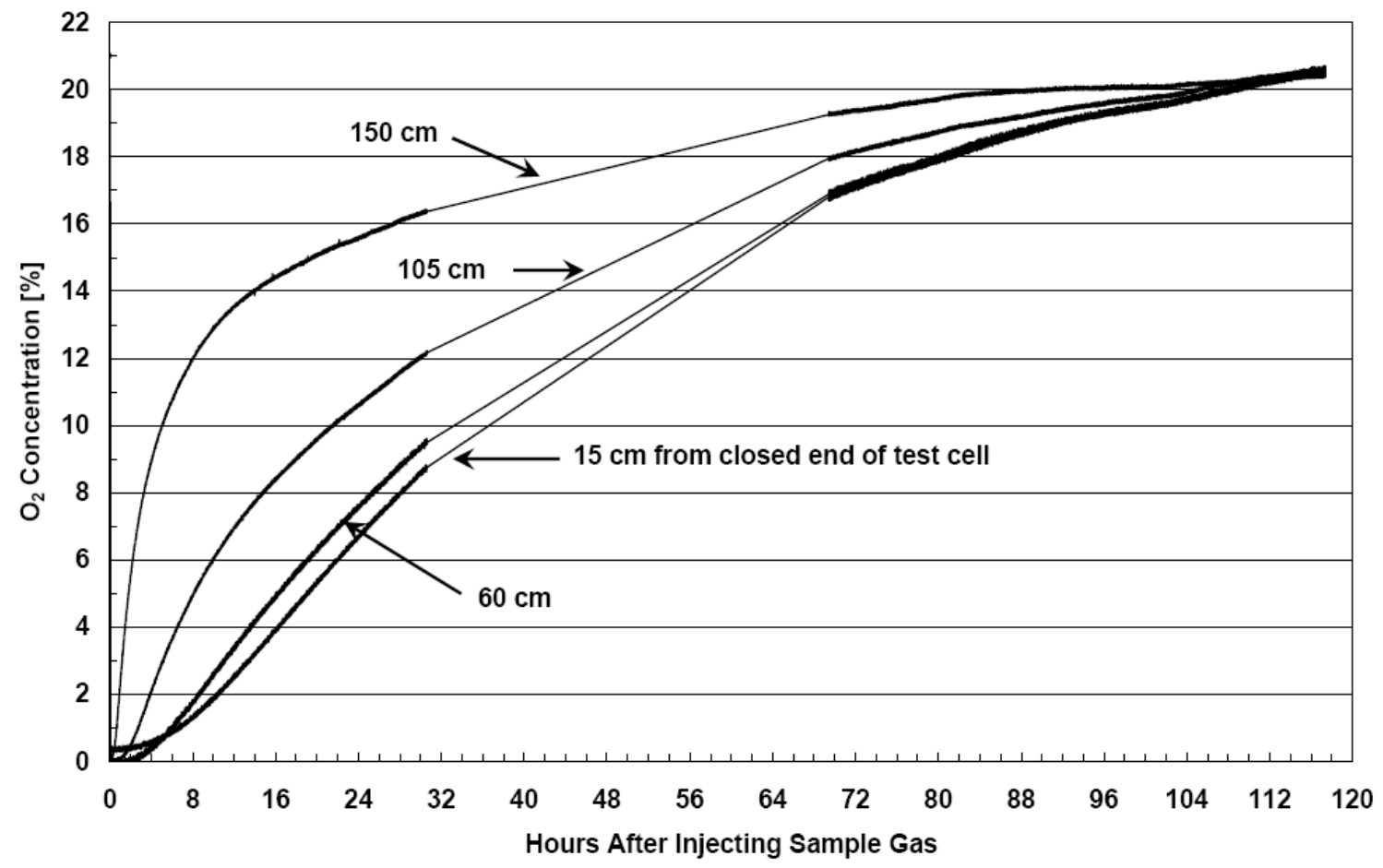

Figure 6. Sulfur hexafluoride gas diffusion in air following flooding the test cell with $\mathrm{SF}_{6}$. 


\section{OXYGEN DEFICIENCY HAZARD ABATEMENT}

The diffusion of gas in air, particularly helium, was higher than originally expected. However, diffusion rate time scales are very slow relative to oxygen deficiency hazard abatement. As a result, for the large quantity of $\mathrm{SF}_{6}$ in the new Pelletron accelerator, we needed to explore alternatives for $\mathrm{ODH}$ abatement.

We built a $1 / 24^{\text {th }}$ scale model of the Pelletron building and pit out of plywood. The building is $30 \mathrm{~m}$ long, $13 \mathrm{~m}$ wide and $10 \mathrm{~m}$ high with a $14 \mathrm{~m}$ long pit, $8.5 \mathrm{~m}$ deep at one end which houses the Pelletron. The model was instrumented with the oxygen monitors used in the diffusion cell tests. A scaled amount of $\mathrm{SF}_{6}$ was released into the pit of the model, representing a full release. The oxygen monitors were positioned, relative to the scale, $0.6 \mathrm{~m}, 1.8 \mathrm{~m}$ and $5.4 \mathrm{~m}$ from the pit floor, as well as at ground level on the main floor. If the $\mathrm{SF}_{6}$ were perfectly stratified, it would fill the bottom $3 \mathrm{~m}$ of the pit.

In the first spill test, we quickly emptied the scaled quantity of $\mathrm{SF}_{6}$ into the model. The velocities used to release the $\mathrm{SF}_{6}$ were high enough to efficiently mix the $\mathrm{SF}_{6}$ with all the air of the scaled model. The lowest oxygen reading was greater than $18 \%$. A second test was performed taking care to significantly reduce the velocity of the $\mathrm{SF}_{6}$ in order to achieve stratification in the pit. In this test, a 3\% oxygen reading was achieved near the pit floor.

The first spill test as well as the helium spill in the Tevatron tunnel discussed earlier suggests that once a spill gas is mixed with the air, it tends to stay mixed, despite large differences in molecular weight. The relative ease at which a spill gas mixes with air held promise for a solution to the Pelletron $\mathrm{ODH}$ abatement. By mixing the entire $490 \mathrm{~m}^{3}$ of stored inventory of $\mathrm{SF}_{6}$ with the $5,000 \mathrm{~m}^{3}$ building air, we would be able to achieve a minimum oxygen concentration of about $19 \%$.

It was decided to add high volume circulating fans on three of the four walls of the pit area. Each fan was installed half way up the center of the pit wall and was aimed at a $45^{\circ}$ angle down and toward the side. The fans are activated by oxygen monitors placed at various locations in the pit. They blow bulk building air down into the pit to expedite mixing. The three fans result in a clockwise swirling in the pit area. Tests showed that a single fan will adequately mix the $\mathrm{SF}_{6}$ with the building air. Three fans were installed in order to reduce the probability of a fan not operating on demand. The system is tested every six months.

\section{CONCLUSIONS}

Gas diffusion tests with air were performed using gases that are common to ODH analyses at Fermilab. Experimental results for helium and $\mathrm{SF}_{6}$ were presented. Simulations were made which compared well to helium and $\mathrm{SF}_{6}$ experimental results.

Experiments were performed to understand how easily gases much lighter or heavier than air would mix with air and whether they remained mixed. The results showed that modest gas velocities will fully mix the spilled gases with air. The gases remained fully mixed over long distances in tunnels, or for long times in enclosed spaces.

These results were applied to $\mathrm{ODH}$ abatement for a new system which utilizes large quantities of $\mathrm{SF}_{6}$. Knowing the results allowed us to implement control measures that were reasonable in cost and had built-in redundancy.

$\mathrm{ODH}$ abatements which relied on stratification of the gases need to be reanalyzed to consider how the results of this work affect personnel safety. Systems which utilize ceiling 
lintels in an attempt to contain helium or low exhaust ventilation suction points to draw heavier gases may not be effective in controlling ODH hazards.

\section{ACKNOWLEDGMENTS}

Fermilab is operated by Universities Research Association Inc. under Contract No. DE-AC02-76CH03000 with the United States Department of Energy.

\section{REFERENCES}

1. Fermilab ES\&H Manual, Chapter 5064, "Oxygen Deficiency Hazards (ODH)," December 2003.

2. Theilacker, J. C., "Oxygen Monitoring Cells at Fermilab," in XXI' International Congress of Refrigeration, International Institute of Refrigeration, France, 2003.

3. Bird, R.B., Stewart, W.E. and Lightfoot, E.N., Transport Phenomena, John Wiley \& Sons, New York, 1960.

4. F-Chart Software, Engineering Equation Solver Users Manual, http://www.fchart.com, 2005. 